\title{
Managing the Mind, Body, and Soul-Closing the Gap Between Managers and Young Employees With Anxiety Disorders
}

\author{
Debra Hunter \\ Troy University \\ Charles Chekwa \\ Troy University
}

Younger generational cohorts are entering the workforce with much higher rates of reported mental illnesses than their predecessors. Academic stress, anxiety, and depression are a major cause of concern among college students. The 2019 Center for Collegiate Mental Health reported that anxiety is one of the most common diagnosis of students seeking services at university counseling centers. The workplace environment operates under different standards with less flexibility. In fact, educational institutions may be marginally preparing students with accommodations to operate in the real world. Companies required to adhere to Title I of the American Disabilities must only provide "reasonable accommodations" for documented disabilities and the interpretation of what is reasonable is determined by management. Yet, many anxiety-related disabilities are undisclosed to management. Employees fear stigmatization and being shunned for sharing their conditions. In some cases, the anxiety could affect workplace productivity and possibly pre-mature termination if misunderstood. The lack of communication between employees and managers creates a "gap" leading to possible unemployment or discrimination suits. In fact, EEOC discrimination charges filed on behalf of employees who suffer from anxiety increased from 65 in 2006 to 371 in 2019. This increase leads one to believe that managers are not properly addressing employees' mental health. Proper training and development opportunities in mental health related issues may curtail additional lawsuits imposed on organizations. To provide an inclusive workplace environment, managers must be proactive in assessing the holistic needs of employees including support for mental and emotional disabilities. This research contends that Generation $Z$ will have higher expectations than previous cohorts for workplace accommodations to support anxiety, stress, autism, and other mental challenges. These expectations have implications for universities and management training programs designed to embrace the needs of individuals with mental health related issues. Greater attention is warranted on closing the existing gap between management and employees with anxiety related disorders.

\section{INTRODUCTION}

Academic stress, anxiety, and depression are a major cause of concern among college students. The 2019 Center for Collegiate Mental Health reported that anxiety is one of the most common diagnosis of students seeking services at university counseling centers (1). Academic year 2020 presented universities and students with novel academic and personal challenges. Amidst the pandemic, many universities across the world struggled to sustain enrollments and maintain academic rigor. Simultaneously, students shared 
the challenges by adjusting to new learning environments, virtual expectations, and disruptions to their social lives. Additionally, many students and their respective families experienced a sudden loss of income that impacted their economic stability. Some were diagnosed and struggled with COVID-19 while others were traumatized by losses of friends and family members. These factors presented new stressors for students who may already suffered from non-pandemic related hardships.

To minimize the stress, university chancellors, academic deans, and departmental chairs challenged faculty members to extend flexibility and compassion to students during these turbulent times. Flexible arrangements included additional office and/or Zoom hours, extensions on assignments for students experiencing hardships, and empathy for students exhibiting signs of distress. Additionally, many institutions enacted a pass/fail strategy to protect the students with subpar performance. Other universities gave students the opportunity to receive course credit hours in lieu of grades for subpar performance. These provisions proved beneficial for students and helped to minimize both stress and anxiety during turbulent times. In many situations, students feel comfortable disclosing feelings of anxiety and distress to caring instructors and support staff that are willing to listen and provide supportive accommodations. Faculty and staff members are legally mandated to provide modifications, adjustments, and additional support to students with disabilities. The Americans with Disabilities Act of 1990 and Section 504 Rehabilitation Act of 1973 implores institutions to make reasonable accommodations for documented physical and mental limitations of qualified individuals with disabilities. Such accommodations might include changes to the classroom environment, modifications to policies, extensions on course assignments, and additional time to complete assessments. Students needing academic support must simply register with a disability service coordinator. The coordinator will meet with the student to determine the appropriate needs and communicate the accommodations to the student's instructors. Confidentiality of the disability is protected by law. Disclosure of an academic accommodation to anyone other than the professor and appropriate support staff is unnecessary.

\section{UNDERSTANDING THE GAP BETWEEN ACADEMIC AND WORKPLACE ENVIRONMENT}

Yet, a stark contrast exists between the workplace and the nurturing culture of the university environment. Once students graduate, the overwhelming support mechanisms fostered by university faculty and staff may cease to exist for two reasons. First, individuals may be reluctant to disclose mental disabilities to employers due to the negative stigmas associated with the disability. Under the Americans with Disabilities Act, employers cannot discriminate against employees for mental disabilities. Employers aware of the disabilities must provide reasonable accommodations to the employee for the disability. Yet, this accommodation does not preclude an individual's reluctance to disclose this information. This notion holds especially true for individuals entering the workforce with aspirations for advancement and career development. Few onboarding programs provide information and support to newcomers who may struggle with anxiety related issues.

Second, access to trained human resource personnel for mental health accommodations may not be prevalent. Managers are often skilled in their respective areas of expertise and focus on achieving organizational goals and objectives with allocated resources. Recognizing the tale tell signs of individuals experiencing anxiety and understanding their unique needs remains a challenge for managers who lack proper human training in this area. Unlike an academic setting where the student's work is independent from their peers, an employee's work responsibilities may be task interdependent and affect the entire team's productivity.

\section{PURPOSE OF STUDY}

While many colleges and universities work diligently to accommodate students, such accommodations may cease to exist in the workplace. The oversight transitions from an academic support personnel to a manager or supervisor with minimum experience working with employees who suffer with anxiety or other mental health challenges. Since these students become emerging professionals, understanding these 
challenges are critical for their success in the workplace. As Generation Z graduate and enter the workforce, these young recruits are disclosing anxiety more than other generations. According to a 2018 American Psychological Association survey, America's youngest adults (ages 15-21) are most likely of all generations to report poor mental health and more likely to seek professional help for mental health issues. (APA Press, 2018).

Recent current events have been a catalyst for stressful life events that potentially increase one's risk for anxiety disorders. For example, uncertainty surrounding the Covid-19 pandemic remains a stressful event for many Americans. Aside from the health risk of contracting a deadly virus, many Americans suffered from unemployment and the ability to provide housing and food for their families. Events surrounding the Black Lives Matter movement, police brutality, and social justice issues serve a constant reminder to minorities of systemic racism and racial disparities in our nation. Unfortunately, the effects of these events pervade the entire nation and its organizations that employ the American workforce.

While such disclosures are important for understanding and addressing these issues, managers must be aware of this trend to prepare for the workplace behaviors observed among these individuals. Considering the psychological and physiological effects of anxiety on an individual, one's reaction to has an adverse impact on employee performance in the workplace. Employees who suffer from anxiety and stress in the workplace may withdraw by exhibiting absenteeism, lack of engagement in job related activities, and eventually turnover. In situations where leaving the job is impossible, employees may create problems for peers and managers including irritability, difficulty getting along with others, lack of concentration and performance inefficiency, inefficient use of time and resources, and difficulty completing work tasks. And since the work of employees is interdependent, these behaviors have the potential to cause a spill-over effect on employees and causing morale issues among team and department members.

The purpose of this study illuminates the impact of anxiety among individuals in the workplace and identifies individual, social, and environmental elements that contribute to present day anxiety among many individuals. The author suggests increasing consumption of social media, the rise in social justice issues, and the COVID-19 pandemic are contemporary factors that contribute to escalating levels of anxiety among working individuals. The literature review also provides practical and insightful ways managers can improve anxiety among individuals in the workplace.

\section{ANXIETY AND INCREASED SOCIETAL FACTORS}

Anxiety is described as an excessive, intense, or persistent worry and fear about everyday situations. Anxiety is a normal part of life for many individuals and presents in many forms including generalized anxiety-social anxiety, pos-traumatic stress disorder (PTSD) obsessive-compulsive disorder (OCD), phobias, and panic attacks to name a few. Mild cases of anxiety related disorders may not disrupt normal day-to day activities. However, chronic anxiety can interfere with an individual's quality of life and has serious implications for an individual's physical health. In fact, long-term anxiety and panic attacks cause the brain to regularly release stress hormones. Increased stress hormones can increase the frequency of physiological effects symptoms. Psychological effects of anxiety include gloomy moods, irritability, difficulty concentrating, and depression. Symptoms of depression include feelings of hopelessness, lost interest in activities once enjoyed, and social withdrawal from others.

Physical or bodily reactions to anxiety may include dizziness, headaches from constant worrying and stress, rapid breathing, sweating, digestive issues, heart palpitations, fatigue, and loss of libido. Anxiety related disorders may also raise the risk of high blood pressure, heart disease or other coronary events. Repeated feelings of anxiety and stress for extended periods of time also impede the body's ability to function normally and ultimately weakens the immune system. A weakened immune system makes individuals more susceptible to viral infections and other illnesses.

While anxiety disorders can happen during any life stage, most individuals most begin by middle age. Yet, increasing substance abuse problems, societal pressures, and competition among teens and younger adults may challenge timing of the onset of anxiety disorders. Gender discrepancies in individuals suffering 
from anxiety related problems have also been noted. According to the National Institute of Mental Health, women are more likely to have an anxiety disorder than men.

\section{Increase in Anxiety and Social Media Consumption}

Humans are social creatures and inherently seek social belonging to groups in society. Given the rise in social media platform usage, more attention is being given to virtual connections and the impact these connections have on human well- being. Technological advancements have made receiving information simpler and more addictive through any social media platform of our choice. Popular social networking sites include Facebook, LinkedIn, Pinterest, Twitter, and Instagram. Growth in popularity of other platforms such as Snapchat and Vine demonstrate the dynamic nature of social networking sites. Recently, TikTok has joined the ranks of social media and is becoming increasingly popular among Americans. Moreover, younger generations have a constant need to stay connected to their friends' social media updates. For college students, usage of social media is an addictive behavior and serves as a channel for communication, entertainment, knowledge, and self-expression (Kim, Jeong, \& Lee, 2010). Thus, variety, ease of use, and repeated exposure to various social media platforms makes it easier for individuals to compare their lives to the lives of others observed through online postings and pictures depicting splices of life. Such comparisons may or may not be beneficial for self-enhancement purposes.

Social Comparison Theory postulates that people determine their own personal worth based on how they compare to others (Festinger, 1954). According to this theory, individuals are driven to gain accurate self-evaluations by comparing themselves to others to reduce uncertainty. In situations of uncertainty, people will compare and evaluate themselves to others and form an opinion of self. Both upward and downward comparisons may occur. When an individual feels inadequate, esteem issues occur. Low selfesteem is a risk factor for social anxiety and depression (Sowislo \& Ortho, 2012). DeJong (2012), reported an association between low implicit self-esteem and social anxiety, especially among females. In some instances, observations on social media sites may cause individuals with low self-esteem to feel less satisfied with their self -images and lives. Feelings of inadequacy may occur when individuals are exposed to a situation where the self is seen as lesser in some regard (Seu, 2006). Extensive literature suggests a positive correlation between low self-esteem and high levels of anxiety (De Jong, Sportel, de Hullu \& Nauta, 2012).

Excessive exposure to social media has the potential to trigger anxiety related events. In fact, prior research has indicated that irritability, anxiety, and feelings of inadequacy are intensified when individuals view social media (JWT Intelligence 2012; Worthham, 2011). Individuals with higher level of irritability may act impulsively or rudely at the most minuscule disagreement or slightest frustration level (Caprara et al., 1985).

Hence, the feelings of inadequacy have the potential to trigger a stressful and negative response. Thus, when individuals feel apprehensive, fearful, and uneasy upon checking social media sites, their anxiety and irritability may temporarily increase. This temporary increase in anxiety may lead to hostile attitudes towards peers in the workplace and may negatively impact interpersonal relationships in the workplace.

\section{Increased Evidence of Institutional Racism and Discrimination}

Institutional racism and discrimination also serve as potential stressors for minorities that affect and personal and professional lives. This phenomenon occurs when the affected group members are denied employment and educational opportunities, housing in certain geographical locations, and other public services. Discrimination in the workplace may be subtle or overt and has adverse consequences for minority groups involved. In fact, discriminatory practices among minorities and its impact on their mental health is a major public health problem in the United States. Over the years, many studies have been conducted to understand the relationship between racial discrimination and the mental health of African Americans. Ayalon and Gum (2011) reported that $30 \%$ of the general population reported at least one major lifetime discrimination, but $45 \%$ of African Americans reported more discriminatory events than other groups and the greatest frequency of everyday discrimination. Everyday discrimination indicated a stronger correlation with mental health disorders. Prior research studies have established the strong association between racial 
discrimination and anxiety symptoms relative to other psychiatric symptoms (Pieterse, Todd, Neville, \& Carter, 2012) and the existence of anxiety in the general population (Kessler, Chiu, Demler, Merikangas, \& Walters, 2005).

Unfortunately, racial discrimination is a pervasive and normative experience for African American youth (Hope, Hoggard, \& Thomas, 2015) that is associated with mood disorders (Paradies et al., 2015), decreased self-esteem (Yip, 2015), and cardiovascular disease (DeLilly \& Flaskerud, 2012). Racial discrimination may increase symptoms of anxiety because such discriminatory experiences can increase sensitivity within interpersonal interactions (Neblett et al, 2016), reduce self-esteem (Yip, 2015), and deplete cognitive resources (Salvatore \& Shelton, 2007; Smith, Allen, \& Danley, 2007). Furthermore, the discriminatory acts may lead to psychological and biological stress responses (Sawyer, Major, Casad, Townsend, \& Mendes, 2013) that can increase anxiety. From a management perspective, these factors have important implications for an individual's cognitive work-related abilities, interpersonal relationships with peers, self-efficacy and self-esteem on the job.

As these individuals grow older, they may encounter increased discrimination. Repeated exposure to racial discrimination may lead to distress and anxiety. Increased exposure may be experienced either through direct victimization or through indirect observations of discrimination depicted in the news media. In recent years, the media has illuminated the disparities of racially motivated hate crimes and other discriminatory practices that plague the nation. With respect to age and gender, these acts of injustice vary among minority victims. The death of Ahmaud Arbery, an unarmed 25-year-old black man who was pursued and fatally shot on February $23^{\text {rd }}, 2020$ serves as tragic reminder of violent crimes against minority youth. One month later, Beyonna Taylor, a 26- year-old African American female was shot and killed by a police officer during a raid on her apartment. On May 25, 2020, the country witnessed yet another tragedy. George Floyd, a 46- year- old black man, was killed as a police officer fatally knelt on his neck for fifteen seconds. These events not only led the nation on a massive demonstration against discrimination against minorities, but also initiated conversations and actions in many business organizations on racial discrimination and disparities among minority employees.

Despite widespread vocalization denouncing acts of discrimination, some minorities continue to suffer in silence at the hands of discrimination in the workplace. In some instances, individuals are forced to internalize racism to sustain their lives and livelihood as a minority group. Internalized racism is a process in which individuals internalize and accept dominant White cultures beliefs and actions towards Black people and reject both African American culture and ideas (Bailey, Chung, Williams, Singh, \& Terrell, 2011). Such experiences have manifested the professional work environment. Moreover, internalized racism has been positively associated with depression and psychological distress for both foreign-born and American-born individuals (Mouzon and McLean, 2017). Reports of racially discriminatory behaviors toward Americas in the United States has increased during the COVID-19 pandemic including microaggressions and hate crimes. In fact, research results indicate that nearly $30 \%$ of Asian Americans reported an increase in discrimination, and over $40 \%$ reported an increase in depressive symptoms, sleep difficulties, and anxiety (Lee, S., \& Waters, S. F., 2020). The negative psychological effects of discrimination are relevant to various ethnic groups and warrant greater attention for managers and leaders of diverse groups.

\section{Covid-19 Pandemic as an Anxiety-Induced Stressor}

Exposure to stressors has a tremendous impact on attitudes and behaviors (Weiss \& Cropanzano, 1996). Moreover, exposure to stressors characterized by uncertainty and existing threats lead to anxiety (Lazarus, 1991). The stress response to the COVID-19 virus emerges from an individual's appraisal of a situation to be harmful and difficult to resolve.

The COVID-19 pandemic is an anxiety inducing stressor that presents uncertainty and an ongoing threat that cannot be avoided by societal members. One of the most straightforward characteristics of a stressor is its intensity (Bledow et al., 2011). During the crisis, individuals are increasingly exposed to media information on the total number of confirmed cases, the daily increase in cases, and the exponential growth or decline of case numbers, the number of hospitalizations and the number of deaths. More cases within 
ones' environment (i.e. state, city, community, school district, etc.) will result in greater appraisals of an imminent threat. More cases also signify a greater risk of one getting sick and increased disruptions for one's personal life (employment, family, schooling) and the economic environment in general. These factors combined contribute to elevated levels of uncertainty and threats which ultimately leads to anxiety.

Manifestations of viral contractions can range from asymptomatic, mild, severe, and deadly. Since individuals may vary in the degree to which severe symptoms are experienced, much uncertainty exists around the possibility of contracting the virus and the immune system's response. According to the CDC, individuals of advanced age are the highest risk for unfavorable outcomes of contracting the virus. Also, minorities (Blacks and Hispanics) have suffered disproportionately from the disease. Thus, anxiety related emotions centered around the virus may be higher for both minorities and older individuals. These groups represent a significant majority of the nation's workforce and may exhibit more on the job anxiety than other groups regarding the COVID-19 virus.

For example, anxiety about contracting in the workplace could have a detrimental effect on an employee's cognition and attention that will ultimately affect both attitude and behavior. For example, anxiety creates a state of hypervigilance (Cheng \& McCarthy, 2018; Ellis, 1962), which increases attention to threats and exaggerates them (Grupe \& Nitschke, 2013). In the workplace, an individual in a hypervigilant state may be more focused on the anticipated threat and less attentive to tasks and responsibilities of the job itself. Second, anxiety evoking experiences can not only impeded attentional processes, but also consume individual resources (cognitive thinking ability, creativity, and problem solving skills) and interfere with recovery (Kagan, 1972; Sonnetag, 2017). Anxious individuals tend to ruminate more (Thau \& Mitchell, 2010). Rumination further depletes cognitive resources which leads to emotional exhaustion (Maslach, 2001). Hence, the anxiety related behaviors serve as a distractor and prohibit cognitive resource mobilization that results in lowered work engagement. This confirms the notion that persistent and unresolved stressors (such as a lingering pandemic) are negatively associated with engagement (Sonnentag, 2010). These disruptions also interfere with task performance (Eysenck, 2007) and lead to avoidance behaviors (Spector and Fox, 2002). Hence, researchers have surmised a negative relationship between anxiety and job performance (Ford, 2011). The COVID-19 pandemic's effect on an individuals' anxiety may negatively impact job performance for the reasons mentioned above.

\section{OHIO AND MICHIGAN STATE STUDIES -LEADERSHIP SUPPORT}

While early attempts to study leadership focused on personal attributes and traits to determine leader effectiveness, Ohio State University researchers shifted the focus from traits to behavioral of leaders (Bass, 1990; Yukl, 2002). Their efforts identified two broad categories of leadership behavior that account for effective leadership: consideration and initiating structure. Examples of behaviors that are high on initiating structure include settings standards and goals, coordinating work activities of subordinates, emphasizing deadlines, monitoring compliance with procedures, problem solving, and establishing channels of communication. On the other hand, the construct of consideration behavior reflects a leader's concern for the welfare of subordinates and a genuine desire to foster good interpersonal relationships among group members. Researchers at Ohio State identified consideration behaviors as expressing concern for subordinates, listening to them, consulting with subordinates and adhering to their advice, treating them as equals, appreciating and recognizing their work, reiterating job satisfaction, and supporting them emotionally.

Simultaneously, researchers at the University of Michigan conducted a similar study using interviews to identify effective leadership behavior. They identified two- dimensions of leadership behavior related to effectiveness: employee-orientation and production-orientation (Katz \& Katz, 1960). The employeeoriented leaders supported interpersonal relations similarly to the consideration behaviors identified in the Ohio-State studies. These leaders emphasized keeping subordinates informed, giving employees more discretion, involving subordinates in decision making, and acting in a friendly and supportive manner.

Conversely, production- oriented leaders focused on the task aspects of the job and focused on goal setting, obtaining necessary resources for task accomplishment, planning and organizing work, and setting goals. 
While both behaviors are necessary to accomplish organizational goals, individuals may vary on the degree to which either dimension is practiced in a work environment. Some leaders may be high on consideration and low on initiating structure and vice versa.

Upon completion of these studies, researchers in both universities surmised that relation-oriented behaviors are positively correlated to job satisfaction (Bass, 1990; Stodgdill, 1965; Yulkl, 2002). Furthermore, results also indicate that relations-oriented leadership styles can increase work performance. One may surmise that caring and supportive leadership lead to improved communication and cooperation among subordinates. As such, these individuals demonstrate a stronger commitment to their teams and organizations overall.

For purposes of this study, we focus on Ohio State's research on consideration behavior and Michigan State's research on employee-orientation. Both studies illuminate the need for supportive behaviors and concern for an individual's emotional welfare. A recent study found that social support significantly buffered the effect of discrimination on depressive symptoms (Lee, S. \& Walters, S., 2020). And given the rise in anxiety and depression related behaviors, greater emphasis needs to be placed on leader behaviors that address these problems. However, to support an employee emotionally, two important things must occur. First, employers must recognize red flags associated with employees experiencing emotional distress. As an increasing number of employees experiencing anxiety related disorders matriculate into organizations, identification of emotionally distressed individuals is paramount. Second, employers should be knowledgeable of resources available for employees and implement intervention strategies to help employees cope with certain stressful situations.

\section{IMPLICATIONS FOR MANAGERS}

Given the rise in anxiety levels among Generation $\mathrm{Z}$ and Millennials, managers are seeking new ways support employees. Recognizing anxiety-related work behaviors, empathizing with employees dealing with anxiety, providing appropriate resources and evaluating performance on a regular basis are important steps leaders can take to support employees. While leaders will not eliminate anxiety among employees, supportive behaviors will motivate employees to persevere during challenging times. Establishing a good rapport with employees and providing emotional support to individuals suffering from anxiety is paramount to an organization's success. Managers can also demonstrate supportive actions in numerous ways.

To address the rise in social media use among individuals and anxiety addressed by the social comparison theory, employers can create an environment free of social media and the comparisons and competition it breeds (refraining from comparing career progress to others). While organizations cannot control for individual comparisons made with peers outside of the workplace, employers can minimize the stress and anxiety created when employees are encouraged to compete among each other via the company intranet and other internal organizational platforms. Although competition between departments is an encouraged practice, organizational induced peer to peer competition may serve as a breeding ground for anxiety and other stress related illnesses and should be kept to a minimum.

Additionally, many companies offer medical benefits that cover mental health services in the form of psychological counseling. Yet, these services often require employees to independently seek professional help outside of normal work hours. While opportunities to participate in Zoom sessions have proved beneficial, many employees experience challenges securing appointments with providers outside of the normal work hours. Thus, organizations should consider expanding wellness programs within organizational campuses to include on-site social workers and other licensed providers that may provide confidential services to employees. In addition to counseling, many establishments have also incorporated many wellness activities into the standard workday such as yoga, masseuse and on-site spa services.

To address the discriminatory practices, organizations should focus on creating a more inclusive and open environment for all ethnic groups. Since most organizations require an annual ethics training for employees, incorporating additional curriculum to help minimize the effects of discrimination and implicit bias would prove beneficial. Such training should not only address discriminatory behavior, but also addresses implicit biases that impact decision making in the workplace. Providing a safe space for 
employees to participate in open dialogue addressing diversity and inclusion concerns is also essential. Educating managers and employees alike can minimize the potential for covert and overt discriminatory practices that adversely affect minority groups in the workplace.

Finally, educating employees on discriminatory practices, companies can also offer mental health first aid training to help employees recognize the warning signs of anxiety in colleagues. Understanding the warning signs of employees in distress and suffering from anxiety are critical in providing the appropriate resources and assistance employees need. Also, educating employees on the detrimental effects of anxiety may help those suffering from symptoms that could potentially impede job performance.

\section{REFERENCES}

APA Press. (2018). Stress in American Generation Z. Retrieved from https:www.apa.org/news/press/release/stress/2018/stress/-gen-z.pdf

Ayalon, L., \& Gum, A. (2011). The relationships between major lifetime discrimination, everyday discrimination, and mental health in three racial and ethnic groups and older adults. Aging \& Mental Health, 15(5), 587-594.

Banks, K.H., Kohn-Wood, L.P., \& Spencer, M. (2006). An examination of the African American experience of everyday discrimination and symptoms of psychological distress. Community Mental Health Journal, 42, 555-570.

Bass, B.M. (1990). Bass and Stogdill's handbook of leadership: Theory, research, and managerial applications (3rd ed.). New York: Free Press.

Beck, A.T., \& Young, I.E. (1978). College blues. Psychology Today, 12(4), 80-82.

Bledow, R., Schmitt, A., Frese, M., \& Kuhnel, J. (2011). The affective shift model of work engagement. Journal of Applied Psychology, 96(6), 1246-1257.

Caprara, G., Cinnanni, V., D’Imperio, G., Passerni, S., Renzi, P., \& Travaglia, G. (1985). Indicators of impulsive aggression: Present status of research on irritability and emotional susceptibility scales. Personality and Individual Differences, 6, 665-674.

Center for Collegiate Mental Health. (2020). 2019 annual report. University Park, PA: Penn State University. Retrieved from https://ccmh.memberclicks.net/assets/docs/2019-CCMH-AnnualReport 3.17.20.pdf

Cheng, G.H., \& McCarthy, J.M. (2018). Understanding the dark and bright sides of anxiety: A theory of workplace anxiety. Journal of Applied Psychology, 103(5), 537-560.

De Jong, P., Sportel, B., Hullu, E.D., \& Nauta, M. (2012, March). Co-occurrence of social anxiety and depression symptoms in adolescence: Differential links with implicit and explicit self-esteem. Psychological Medicine, 42(3), 475-484.

DeLilly, C.R., \& Flaskerud, J.H. (2012). Discrimination and health outcomes. Issues in Mental Health Nursing, 33, 801-804.

Ellis, A. (1962). Reason and emotion in psychotherapy. Stuart.

Eyenck, M.W., Derakshan, N., Santos, R., \& Calvo, M.G. (2007). Anxiety and cognitive performance: Attentional control theory. Emotion, 7(2), 336-353.

Ford, M.T., Cerasoli, C.P., Higgins, J.A., \& Deseare, A.L. (2011). Relationships between psychological, physical, and behavioral health and work performance: A review and meta-analysis. Work and Stress, 25(3), 185-204.

Grupe, D.W., \& Nitschke, J.B. (2013). Uncertainty and anticipation in anxiety: An integrated neurobiological and psychological perspective. Nature Reviews Neuroscience, 14(7), 488-501.

Hope, E.C., Hoggard, L.S., \& Thomas, A. (2015). Emerging into adulthood in the face of racial discrimination: Physiological, psychological, and sociopolitical consequences for African American youth. Translational Issues in Psychological Science, 1, 342-351.

JWT Intelligence. (2012, March 7). Fear of Missing Out. Retrieved from http://www.jwtintelligence.com/wp-content/uploads/2012/03/F_JWT_FOMO-update 3.21.12pdf

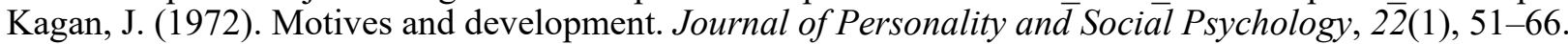

Katz, D., \& Kahn, R.L. (1952). Some Recent Findings in Human Relations Research in Industry. In G.E. Swanson, T.M. Newcomb, \& E.L. Hartley (Eds.), Readings in Social Psychology (revised). Henry Holt and Company 1952. 
Kessler, R.C., Berglund, P., Demler, O., Jin. R., Koretz, D., Merikangas, K.R., \& The National Comorbidity Survey Replication. (2003). The epidemiology of major depressive disorder: Results from the National Comobidity Survey Replication. (NCS-R). Journal of the American Medical Association, 289, 3095-3015.

Kim, W., Jeong, O.R., \& Lee, W.W. (2010). On Social Web sites. Information Systems, 35, 215-236. Lazarus, R.S. (1991). Emotion and adaption. Oxford University Press.

Lee, S., \& Waters, S.F. (2020). Asians and Asian Americans' experiences of racial discrimination during the COVID-19 pandemic: Impacts on health outcomes and the buffering role of social support. Stigma and Health. Advance online publication. https://doi.org/10.1037/sah0000275

Mouzon, D.M., \& McLean, J.S. (2017). Internalized racism and mental health among African Americans, U.S.-born Caribbean Blacks, and foreign-born Caribbean Blacks. Ethnicity and Health, 22, 3648.

Neblett, E.W., Jr., Bernard, D.L., \& Banks, K.H. (2016). The moderating roles of gender and socioeconomic status in the association between racial discrimination and psychological adjustment. Cognitive and Behavioral Practice, 23, 385-397.

Paradies, Y.C. (2006). A systematic review of empirical research on self-reported racism and health. International Journal of Epidemiology, 35, 888-901.

Pieterse, A.L., Todd, N.R., Neville, H.A., \& Carter, R.T. (2012). Perceived racism and mental health among Black American adults: A meta-analytic review. Journal of Counseling Psychology, 59, $1-9$.

Salvatore, J., \& Shelton, J.N. (2007). Cognitive costs of exposure to racial prejudice. Psychological Science, 18, 810-815.

Sawyer, P.J., Major, B., Casad, B.J., Townsend, S.S.M., \& Mendes, W.B. (2012). Discrimination, internalized racism, and depression: A comparative study of African American and AfroCaribbean Blacks. Ethnicity \& Health, 22, 36-48.

Seu, B.I. (2006). Shameful Selves: Women's feelings of inadequacy and constructed facades. European Journal of Psychotherapy \& Counseling, 8(3), 285-303.

Smith, W.A., Allen, W.R., \& Danley, L.L. (2007). "Assume the position...you fit the description": Psychosocial experiences and racial battel fatigue among African American male college students. American Behavioral Scientist, 51, 551-578.

Sonnentag, S., Dormann, C., \& Demerouti, E., (2010). Not all days are created equal: The concept of state work engagement. In A.B. Bakker \& M.P. Leiter (Eds.), Work engagement: Recent Developments in Theory and Research (pp. 25-38). Psychology Press.

Sonnentag, S., Venz, L., \& Casper., A. (2017). Advances in recovery research: What have we learned? What should be done next? Journal of Occupational Health Psychology, 22(3), 365-380.

Sowislo, J.F., \& Ortho, U. (2012, June 25). Does Low Self-Esteem Predict Depression and Anxiety? A Meta-Analysis of Longitudinal Studies. Psychological Bulletin.

Stodgill, R.M. (1965). Managers, employees, organizations: A study of 27 organizations. Bureau of Business Research Monograph, 125. Ohio State University .

Thau, S., \& Mitchell, M.S. (2010). Self-gain or self-regulation impairment? Tests of competing explanations of the supervisor abuse and employee deviance relationship through perceptions of distributive justice. Journal of Applied Psychology, 95(6), 1009-1031.

Weiss, H.M., \& Cropanzano, R. (1996). Affective events theory: A theoretical discussion of the structure, causes and consequences of affective experiences at work. In B.M. Staw \& L.L. Cummings (Eds.), Research in organizational behavior: An annual series of analytical essays and critical reviews (Vol. 18, pp. 1-74). JAI Press.

Worthham, J. (2011, April 9). Feel like a wallflower? Maybe it's your Facebook wall. Retrieved May 2012, from http://www.nytimes.com/2011/04/10/business/10ping.html.

Yip, T. (2015). The effects of ethnic/racial discrimination and sleep quality on depressive symptoms and self-esteem trajectories among diverse adolescents. Journal of Youth and Adolescence, 44, 419430.

Yukl, G. (2002). Leadership in organizations (5th ed.). Upper Saddle River, NJ: Prentice Hall. 